\title{
Perception and risk factors for cervical cancer among women in northern Ghana
}

\author{
Constance A. Opoku ${ }^{1}$, Edmund Nii Laryea Browne ${ }^{2}$, Kathryn Spangenberg ${ }^{3}$, Cheryl Moyer ${ }^{4}$, David \\ Kolbilla $^{5}$ and Katherine J. Gold ${ }^{6}$
}

Ghana Med J 2016; 50(2): 84-89 DOI:_http://dx.doi.org/10.4314/gmj.v50i2.6

\begin{abstract}
${ }^{1}$ Department of Medicine, Tamale Teaching Hospital, P.O.Box 16, Tamale, Ghana ${ }^{2}$ Department of Community Health, Ghana College of Physicians and Surgeons, Accra, Ghana ${ }^{3}$ Family Medicine Unit at Polyclinic Directorate, Komfo Anokye Teaching Hospital, Kumasi, Ghana ${ }^{4}$ Department of Medical Education, University of Michigan Medical School, Ann Arbor, Michigan, ${ }^{5}$ Department of Obstetrics and Gynaecology, Tamale Teaching Hospital, Tamale, Ghana ${ }^{6}$ Department of Family Medicine and Department of Obstetrics and Gynecology, University of Michigan, 1018 Fuller Street, Ann Arbor, MI, USA
\end{abstract}

Corresponding author: Constance A. Opoku

Email: cafraopoku@yahoo.com

Conflict of interest: None declared

\section{SUMMARY}

Objective: This study assessed the perception of risk of cervical cancer and existence of risk factors for cervical cancer based on five known risk factors among women attending the Tamale Teaching Hospital in Tamale, Ghana. Methods A consecutive sample of 300 women was interviewed using a semi-structured questionnaire to inquire about risk factors and perception of risk of cervical cancer. Specific risk factors that were explored included early coitarche, multiple sexual partners, polygamous relationships, history of smoking, and having a current partner who had multiple sexual partners.

Results: Sixty-one per cent of women reported that they had no personal risk for cervical cancer. $27 \%$ of respondents were in polygamous relationships, and of those, more than half didn't think they were at an increased risk of cervical cancer. 2 women had a total of $\geq 5$ sexual partners in their lifetime and neither believed they were at any risk for cervical cancer. $23 \%$ said their current partner had had at least 2 sexual partners in his lifetime, and of those, (61\%) thought they were at no risk for cervical cancer. $46 \%$ of respondents reported not having any of the risk factors listed in the study. $23 \%$ of respondents reported having one risk factor while $21 \%$ had two risk factors and $11 \%$ had three or more risk factors.

Conclusion: Women's perception of personal risk for cervical cancer is lower than their actual risk based on the five behavioural risk factors assessed and a lack of knowledge of the personal factors for the disease

Funding: This project was supported by NIH Research Training Grant \#R25 TW009345 funded by the Fogarty International Centre, in partnership with several NIH Institutes (NIMH, NIGMS, NHLBI, OAR and OWH)

Keywords: Cervical Cancer, Risk, Perceptions, Northern Ghana

\section{INTRODUCTION}

In Ghana the cervical cancer incidence rate of 26.4 per 100,000 women per year makes it the most commonly occurring cancer in women. ${ }^{1}$ There are nearly 7 million women aged 15 years and older who are at risk of developing cervical cancer in Ghana ${ }^{1}$

A number of risk factors for cervical cancer are linked to exposure to the human papilloma virus (HPV)., ${ }^{2}, 3$ These include early age of first sexual intercourse ${ }^{4}$, having multiple sexual partners ${ }^{4}$ and having partners who themselves have multiple sexual partners. ${ }^{5}$ Other independent risk factors are infrequent screening for cervical cancer and tobacco use. ${ }^{6}$ While the prevalence of HPV infection is not known in Ghana, about $21.5 \%$ of women in the general population in West Africa are estimated to harbor cervical HPV infection at any given time. ${ }^{1}$

No national screening programme currently exists in Ghana for cervical cancer, although at the time of this study, referral-based screening is available in two urban teaching hospitals which reach a limited number of women. Diagnosis of cervical cancer in the early treatable stages remains relatively rare. ${ }^{7}$ 
A study published in 2000 showed that of the women with cervical cancer who presented to the Korle-Bu Teaching Hospital - the largest teaching hospital in Ghana - $64.3 \%$ presented with stage IIB or worse disease. ${ }^{8}$ Conversely, there have been dramatically reduced rates of cervical cancer in developed countries with well organized-screening and treatment programs. ${ }^{9,10,11}$

Several studies have found that perceived risk is an important predictor of whether individuals change behaviors to reduce risk exposure. ${ }^{12,13,14,15}$ In addition, perception of risk has been found to lead people to initiate actions to reduce risk. ${ }^{16}$ Women's perception of their own risk of cervical cancer often differs from scientific estimates of risk ${ }^{17,18}$, and even when screening facilities are widely available, lack of risk perception often serves as a barrier to screening. ${ }^{19,20,21}$

This study was designed to explore women's perceptions of their own risk of cervical cancer and to determine if risk perceptions were associated with the number or type of risk factors women reported having, that could put them at an increased risk of cervical cancer.

The study was conducted at the antenatal and child welfare clinics of the Tamale Teaching Hospital. The hospital is the referral center for the three northern regions of Ghana, and one of three (3) teaching hospitals in the country; it is the center for clinical training of medical students of the University of Development Studies. The hospital has a 452-bed capacity of which 40 are in the Gynecology Department. Of the number of Gynecology cases admitted each year to the hospital, $2 \%$ are cervical cancer patients. Approximately 220 women access care at the antenatal clinic and 620 women are seen at the child welfare clinic each month.

\section{METHODS}

This study was conducted between February and July 2013 at the antenatal clinic (ANC) and child welfare clinics (CWC) of the hospital. To be eligible for inclusion in the study, women had to be between the ages of 18-45 years; able to communicate in Twi, English or Dagbani (the three most common languages in the region); seeking non-urgent care; and able to provide informed consent.

Female research assistants administered a semistructured questionnaire to each participant in a separate room attached to the clinic, which ensured privacy from the other clinic attendants and the hospital staff. Each participant was given a unique study ID and on completion of the interview was given a token gift such as a bar of soap, body powder or a pack of fruit juice.
The survey collected information about demographic characteristics, knowledge of cervical cancer, risk factors for developing cervical cancer and the respondent's perception of her personal risk for cervical cancer. Using the risk factors of being in a polygamous relationship, first intercourse before age 15, smoking cigarettes, 2 or more sexual partners in one's lifetime, and believing your partner had 2 or more lifetime sexual partners, a risk scale of 0-5 was created with the presence of each risk factor representing one unit of risk. Respondents were then categorized into no risk (having none of the risk factors), low risk (having one risk factor), moderate risk (having two risk factors) and high risk (having 3 or more risk factors).

Attempts to minimize errors on this study included the use of trained research assistants who were fluent in all three languages used in the interviews, thus removing the need for translators. The questionnaires were also translated from English and back translated from all three languages so that questions asked were the same regardless of which language was used. Double entry of data was also done.

The study was approved by the Ethics Review Committee of the Ghana Health Services and the Institutional Review Board of the University of Michigan in the United States.

Data were analysed in STATA statistical software (13.0, College Station drive, TX). Frequencies and descriptive statistics were derived for demographic characteristics, knowledge about cervical cancer, personal risk factors and perception of risk. Relationships of perceived risk and objective risk were determined by cross tabulating relevant determinant variables with these outcome variables. Chi-square statistics were calculated with specified cross tabulations, with significance declared at a pvalue $\leq 0.05$.

\section{RESULTS}

Three hundred and five eligible women were invited to participate in the study. Three women declined participation and two women did not complete the interviews, thus yielding a response rate of $98.4 \%$.

\section{Demographic Characteristics}

Data were collected from 300 participants from February to July 2013 , yielding a response rate of $98 \%$. Overall, most participants in the sample were Moslem (83\%), married $(93 \%)$ and had no more than basic education (primary, junior high school and Islamic school). Less than a fifth of respondents were not involved in any income generating activity and were categorized as unemployed; this category includes homemakers and 
about ten percent of respondents worked in different capacities for governmental institutions, and were categorized as government workers. The mean age was 28 (SD 5.6). Majority of the women had coitarche after age 15. The average number of sexual partners per woman was 1.7 (SD 1.7) and the average number of children per woman was 2.0 (SD 1.5). None of the women had ever smoked. A third of the women $(n=81,27 \%)$ were in a polygamous relationship (Table 1).

Table 1 Socio-demographic characteristics of the study population

\begin{tabular}{|c|c|c|}
\hline Demographic variables & Number & $\begin{array}{l}\text { Percent- } \\
\text { age }\end{array}$ \\
\hline & $n=300$ & \\
\hline \multicolumn{3}{|l|}{ Age group (years) } \\
\hline $18-26$ & 132 & 44.0 \\
\hline 27-35 & 136 & 45.0 \\
\hline $36-45$ & 32 & 11.0 \\
\hline \multicolumn{3}{|l|}{ Religion } \\
\hline Moslem & 249 & 83.0 \\
\hline Christian & 51 & 17.0 \\
\hline \multicolumn{3}{|l|}{ Marital Status } \\
\hline Single & 13 & 4.0 \\
\hline Co-habiting & 9 & 3.0 \\
\hline Married & 278 & 93.0 \\
\hline \multicolumn{3}{|l|}{ Pregnancy Status } \\
\hline Pregnant & 154 & 51.0 \\
\hline Not Pregnant & 140 & 47.0 \\
\hline Not Sure & 6 & 2.0 \\
\hline \multicolumn{3}{|l|}{ Polygamous Status } \\
\hline Polygamous & 81 & 27.0 \\
\hline Non-Polygamous & 219 & 73.0 \\
\hline \multicolumn{3}{|l|}{ Educational Status } \\
\hline No Education & 71 & 24.0 \\
\hline Basic Education & 111 & 37.0 \\
\hline Secondary Education & 62 & 21.0 \\
\hline Tertiary Education & 56 & 18.0 \\
\hline \multicolumn{3}{|l|}{ Occupational Status } \\
\hline Unemployed & 53 & 18.0 \\
\hline Farmers & 4 & 1.0 \\
\hline Traders & 81 & 27.0 \\
\hline Government Workers & 32 & 11.0 \\
\hline Buisness Owners & 69 & 23.0 \\
\hline Other Work & 61 & 20.0 \\
\hline \multicolumn{3}{|l|}{ Insurance Status } \\
\hline No Insurance & 22 & 7.3 \\
\hline $\begin{array}{l}\text { National Health Insur- } \\
\text { ance }\end{array}$ & 274 & 91.3 \\
\hline Other Insurance & 4 & 1.3 \\
\hline
\end{tabular}

\section{Knowledge Of Cervical Cancer}

The majority of respondents $(200,66.7 \%)$ had never heard about cervical cancer. Of the 100 women who had heard about cervical cancer, $23(23 \%)$ reported that they were aware of the risk factors, $17(17 \%)$ said they knew the signs of cervical cancer and 14 (14\%) respondents said they knew how cervical cancer was detected. Only nine respondents (3\%) had been previously screened for cervical cancer

\section{Willingness To Screen}

The majority of the respondents ( $\mathrm{n}=289,96 \%$ ), said they were likely to seek screening for cervical cancer if the facility offered screening services while $9(3 \%)$ said they were unlikely to screen under these conditions.

Most of the women ( $\mathrm{n}=290,97 \%)$ expressed willingness to seek screening for cervical cancer if screening was free. Majority of respondents $(n=229,76 \%)$ were willing to pay at least something for screening but Fourteen $(4.7 \%)$ of women were not willing to pay anything for screening. Fifty-seven (19\%) were noted as being cautiously willing to pay depending on the cost.

\section{Perception Of Risk}

Most women $(184,61.3 \%)$ thought they had no risk for cervical cancer while a smaller number $(101,33.7 \%)$ reported low risk. Even fewer women $(13,4.3 \%)$ perceived themselves at moderate risk and only two women $(0.7 \%)$ considered themselves to be at great risk

We found a significant relationship between perception of risk and willingness to be screened if screening was free $(p<0.05)$ but contrary to expectations, the perception of risk was inversely related to the expression of willingness to be screened. We also found significant relationships between risk perception and highest level of education and these two factors were directly related. Risk perception and willingness to pay for screening were also significantly related and were inversely related (Table 2).

\section{Actual Risk}

Respondent's actual risk of Cervical Cancer, based on an objective assessment, was compared with respondent's perception of risk of cervical cancer. Perceived risk and actual risk (as assessed via the 5-point risk scale) were significantly associated with one another $(p=0.026)$ and had a positive correlation. 
Table 2

Demographic characteristics relationship with perception of risk

\begin{tabular}{|c|c|c|c|c|c|c|}
\hline \multirow[t]{2}{*}{ Variable } & \multicolumn{4}{|c|}{ Perception of Risk } & \multirow[t]{2}{*}{$\mathbf{X}^{2}$} & \multirow[t]{2}{*}{ p-value } \\
\hline & o Risk & Risk & ate $R$ & & & \\
\hline \multicolumn{7}{|l|}{ Age } \\
\hline $18-26$ & 92 & 35 & 4 & 1 & 7.50 & 0.27 \\
\hline 27-35 & 75 & 53 & 7 & 1 & & \\
\hline $36-45$ & 17 & 13 & 2 & 0 & & \\
\hline \multicolumn{7}{|l|}{ Level of Education } \\
\hline None & 51 & 20 & 0 & 0 & 18.60 & 0.03 \\
\hline Basic & 69 & 37 & 4 & 1 & & \\
\hline Secondary & 38 & 22 & 2 & 0 & & \\
\hline Tertiary & 26 & 22 & 7 & 1 & & \\
\hline \multicolumn{7}{|l|}{$\begin{array}{l}\text { Willingness to screen (if } \\
\text { free) }\end{array}$} \\
\hline Not Willing & 5 & 0 & 0 & 1 & 26.70 & 0.00 \\
\hline Willing & 176 & 100 & 13 & 1 & & \\
\hline Maybe & 3 & 1 & 0 & 0 & & \\
\hline \multicolumn{7}{|l|}{$\begin{array}{l}\text { Willingness to pay for } \\
\text { screening }\end{array}$} \\
\hline Not Willing & 9 & 3 & 1 & 1 & 13.60 & 0.03 \\
\hline Willing & 140 & 76 & 12 & 1 & & \\
\hline Maybe & 35 & 22 & 0 & 0 & & \\
\hline \multicolumn{7}{|l|}{ Knowledge of Risk } \\
\hline No Knowledge & 44 & 29 & 4 & 0 & 8.30 & 0.016 \\
\hline Knowledge & 7 & 11 & 5 & 0 & & \\
\hline \multicolumn{7}{|l|}{ Actual Risk } \\
\hline No Factors & 97 & 36 & 2 & 1 & 22.97 & 0.03 \\
\hline One Risk Factor & 33 & 31 & 5 & 0 & & \\
\hline Two Risk Factors & 39 & 19 & 5 & 0 & & \\
\hline Three Risk Factors & 14 & 15 & 1 & 1 & & \\
\hline Four Risk Factors & 1 & 0 & 0 & 0 & & \\
\hline
\end{tabular}

\section{DISCUSSION}

To the best of our knowledge, this is the first study comparing perception of cervical cancer risk to actual risk in Ghana. There have been studies on perception of risk in southern Ghana and a recent study on perception of risk among men - also conducted in southern Ghana ${ }^{23}$ - but previous studies have not compared perception of risk and actual risk.

In more than half of the women, there were at least one of the risk factors assessed. The underestimation of risk was a consistent finding in our study, as were women's lack of knowledge of cervical cancer.
While it may be logical to assume that these two factors are directly related, a similar study conducted in Ken$\mathrm{ya}^{24}$ using women with similar low levels of knowledge on the disease, reported that majority of the Kenyan women thought themselves at relatively high risk of cervical cancer. Nonetheless, our study is consistent with other studies done in Africa demonstrating low levels of knowledge regarding cervical cancer on the continent ${ }^{18,24}$

We found a significant relationship between risk perception and education and a positive correlation between both variables. 
This is not surprising, since it will be expected that more education will be associated with better knowledge about cancer and its risks.

One of the unique observations in this study was the fact that more than a quarter of the women interviewed were in polygamous relationships. This is consistent with the culture in the Northern Region of Ghana which is a highly patriarchal society where Islam is the main religion and this risk factor for cervical cancer has the tendency to be overlooked because of the cultural acceptance of polygamy. Perceived risk was also significantly associated with knowledge of risk factors and willingness to screen which was consistent with data in existing literature. ${ }^{24}$

Notable among our findings was the fact that the higher a woman perceived her risk to be - even when she underestimated that risk - the higher her actual risk for cervical cancer was, based on objective factors. Perception of risk was also significantly related to willingness to be screened, which is consistent with existing data that establishes significance between perceived personal risk and the need for screening. ${ }^{24} \mathrm{~A}$ surprising finding was the fact that the correlation between perception of risk and willingness to screen was negative. We postulate that the fear of the unknown -when it comes to a diagnosis of cancer - could be a deterrent for screening, in a woman who thinks she is likely to test positive.

It is possible that women provided socially acceptable responses since those who reported being willing to screen were not actually asked to do so. This is one of many studies that highlight the gap in knowledge of a very significant public health problem. ${ }^{17,}{ }^{23}$ As at the time of this research, only one facility in the city of Tamale (which is about 9 kilometers away from the Tamale Teaching Hospital), offered free screening for cervical cancer. It could thus be argued that without the provision of screening services, educating women on cervical cancer is moot. However at the beginning of 2014, the Tamale Teaching Hospital started referral - based Visual Inspection with Acetic acid (VIA) followed by colposcopy. Thus, educating women on cervical cancer is likely to become increasingly important as women now have options for screening and treatment.

Limitations of this study include the use of convenience sampling in a hospital setting. This might not necessarily be representative of all women in the Northern Region. We also did not disaggregate the declaration of willingness to screen with actual screening, as we did not offer the opportunity to screen at the time of the interview. Future research that includes a comparison of stated intentions and actual behavior is warranted.
Another limitation of this study is that the number of sexual partners of the respondents or their partnersmight also have been under reported or inaccurate due to women desiring to give socially-acceptable answers or not being aware of their partners' sexual habits/history. Nonetheless, given the assurances of anonymity that women were given, and the private space in which data were collected, we believe women answered as honestly as could be expected given the sensitive nature of the subject.

In conclusion, the self-perception of cervical cancer risk for women in our study was lower than their actual risk, however the higher their perceived risk, the higher their actual risk. The perception of risk was positively related to their willingness to screen for cervical cancer.

It is therefore recommended that women are educated about cervical cancer and associated risks. There is also a need for the provision of low-cost, high quality and readily accessible facilities. These are critical to increasing screening rates and reducing cervical cancer morbidity and mortality. Particular attention needs to be given to women in patriarchal societies where risky behavior such as polygamy is culturally acceptable.

With the initiation of screening in the teaching hospital, it is hoped that widely available platforms such as the antenatal and child welfare clinic could be a place to educate women on cervical cancer and its risks. Further research is needed to explore social and cultural barriers for women now that screening is available.

\section{REFERENCES}

1. WHO/ICO information centre on HPV and cervical cancer (HPV information centre). Human Papilloma virus and related cancers in Ghana. Summary report $2010 . \quad$ URL: http://apps.who,int/hpvcentre/statistics/dynamic/ico /country_pdf/GHA.pdf?CFID $=6615352 \&$ CFTOKE $\mathrm{N}=80076203$.

2. Cotton SC, Sharp L, Seth R, et al. Lifestyle and socio-demographic factors associated with highrisk HPV infection in UK women. $\mathrm{Br} J$ Cancer. 2007;97(1):133-139.

3. Selvin E, Brett KM. Breast and cervical cancer screening: sociodemographic predictors among White, Black, and Hispanic women. Am J PublicHealth. 2003;93(4):618-623.

4. Hulka BS. Risk factors for cervical cancer. $J$ Chronic Dis. 1982;35(1):3-11]

5. Thomas DB, Ray RM, Pardthaisong T, et al. Prostitution, condom use, and invasive squamous cell cervical cancer in Thailand. Am J Epidemiol. 1996;143(8):779-786. 
6. Castellsague X, Bosch FX, Munoz N. Environmental co-factors in HPV carcinogenesis. Virus Res. 2002;89(2):191-199.

7. Barton MB. Frommer M, Shafiq J. Role of radiotherapy in cancer control in low income and middle income countries. Lancet Oncol 2006; 7: 584-95.

8. Nkyekyer K. Pattern of Gynaecological Cancers in Ghana, East Afr Med J 2000; 77 (10): 536.

9. Smith J, Parkin DM. Evaluation and monitoring of cancer screening. Time trends. Evaluation and monitoring of screening programmes. BrusselsLuxemburg: European commission, Europe Against Cancer Programme; 2000.

10. Sankaranarayanan R, Budukh AM, Rajkumar R. Effective screening programmes for cervical cancer in low and middle income developing countries. Bull World Health Organ, Suppl 2001; 79: 954-62.

11. Anderson GH, Boyes DA, Benedet JL, Le Riche JC, Matisic JP, Suen KH, et al Organization and results of the cervical cytology screening programme in British Columbia, 1955-85. BMJ 1988;296: 9758.

12. Becker MH. The health belief model and sick role behavior. Health Educ Monogr. 1974; 2:409-419.

13. Rogers RW. A protection motivation theory of fear appeals and attitude change. $J$ Psychol. 1975;91:93-114.

14. Rogers RW. Attitude change and information integration in fear appeals. Psychol Reports. $1985 ; 56: 179-182$

15. Schwarzer, R. Self Efficacy in the Adoption and Maintenance of Health Behaviours: Theoretical Approaches and a New Model. In: Schwarzer, R., editor. Self-Efficacy: Thought Control of Action. Washington, DC: Hemisphere; 1992.

16. Julia Fehniger, Jennifer Livaudais-Toman, Leah Karliner, et al. The Relationship Between Perceived
Risk of Breast Cancer, Breast Cancer Concern, and Objective Breast Cancer Risk in a Diverse Sample of Women. $J$ Womens Health Volume 00, Number $0,2013$.

17. Denny-Smith T, Bairan A, Page MC. A survey of female nursing students' knowledge, health

18. beliefs, perceptions of risk, and risk behaviors regarding human papillomavirus and cervical cancer. J Am Acad Nurse Pract. 2006; 18(2):62-69.

19. Rosenstock IM. Why people use health services. Millbank Memorial Fund Quarterly. 1966; 44:94127.

20. Mutyaba T, Mmiro F, Weiderpass E. Knowledge, attitudes and practices on cervical cancer screening among the medical workers of Mulago Hospital, Uganda. BMC Med Educ 2006;6(1):13.

21. Basu P, Sarkar S, Mukherjee S, Ghoshal M, Mittal $\mathrm{S}$, Biswas S, et al. Women's perceptions and social barriers determine compliance to cervical screening: results from a population based study in India. Cancer Detect Prev 2006;30(4):369-74.

22. Winkler J, Bingham A, Coffey P, Handwerker WP. Women's participation in a cervical cancer screening program in northern Peru. Health Educ Res 2008;23(1):10-24.

23. Williams MS. Amoateng P. Knowledge and beliefs about cervical cancer screening among men in $\mathrm{Ku}-$ masi, Ghana. Ghana Med J. 2012 Sep: 46(3): 14751

24. Sudenga SL, Rositch AF, Otieno WA, Smith JS Knowledge, attitudes, practices and perceived risk of cervical cancer among Kenyan women. Int J Gynecol Cancer 2013 Jun;23(5): 895-9.

25. Were E, Nyaberi Z, Buziba N. Perceptions of risk and barriers to cervical cancer screening at Moi Teaching and Referral Hospital (MTRH), Eldoret, Kenya. Afr Health Sci 2011;11(1): 58-64. 